\title{
MANEJO COMUNITÁRIO DE LAGOS DE VÁRZEA E O DESENVOLVIMENTO SUSTENTÁVEL DA PESCA NA AMAZÔNIA
}

\author{
David McGrath, Fábio de Castro, \\ Evandro Câmara e Célia Futemma
}

\section{Introdução}

A várzea amazônica é uma das últimas regiões pesqueiras do mundo ainda pouco explorada (Fig. 1). Contudo, durante os últimos trinta anos a intensificação da pesca tem aumentado a pressão sobre os estoques pesqueiros da várzea (Furtado, 1990; Goulding, 1989; Smith, 1985; Junk, 1984b). Embora a pesca amazônica tenha sofrido grandes mudanças, o desenvolvimento da pesca na região está ainda na sua fase inicial (Bayley \& Petrere, 1989). À medida que a pesca se desenvolve, duas estratégias de manejo estão surgindo, uma baseada no modelo convencional de manejo pesqueiro centralizado no Estado, e a outra, no manejo comunitário dos recursos pesqueiros da várzea (McGrath et al. 1993a).

Nesse contexto, o desenvolvimento da pesca amazônica representa um problema e uma oportunidade. Peixes são recursos altamente produtivos e renováveis. Se os recursos pesqueiros são manejados de forma sustentável, integrando as populações locais que atualmente exploram os recursos, eles podem contribuir significativamente para $\mathrm{o}$ desenvolvimento da várzea. Se o recurso pesqueiro é explorado de forma não sustentável, e sem a participação das populações da várzea, a intensificação da pesca pode levar à degradação dos ecossistemas da várzea e à marginalização da população ribeirinha (McGoodwin 1990, Weber 1994). A proposta deste trabalho é avaliar esses dois modelos de manejo em termos de seus impactos sobre as populações, recursos pesqueiros e ecossistemas de várzea, e avaliar até que ponto o modelo de manejo comunitário poderia servir como base para uma estratégia regional de desenvolvimento dos recursos pesqueiros da várzea. Este trabalho é dividido em 
três partes. Na primeira, são apresentadas as características mais importantes dos dois modelos. $\mathrm{Na}$ segunda parte, é avaliado o potencial de cada modelo para o desenvolvimento da pesca amazônica. $\mathrm{Na}$ última seção, são discutidas as principais barreiras para a implementação do modelo de manejo comunitário.

\section{Antecedentes: a intensificação da pesca na várzea e o surgimento do modelo de manejo comunitário}

A atual situação da pesca na Amazônia é resultado da interação de três fatores. Primeiro, mudanças na tecnologia pesqueira, combinado com um aumento na demanda (regional e de exportação) para o pescado amazônico, têm aumentado substancialmente a pressão sobre o recurso (Bayley \& Petrere 1989; Meshkat, 1960). Segundo, com o declínio da produção de juta, que antes representava a base econômica da várzea, a agricultura tem perdido sua função tradicional na economia regional, com isso a mão-de-obra ribeirinha está se direcionando da agricultura para a pesca (Gentil, 1988; Furtado, 1990). Atualmente, a pesca é a principal atividade da economia ribeirinha, e a maior parte dessa população depende da pesca para compor pelo menos, uma parte de sua renda anual (Gentil 1988, McGrath et al. 1993a). Estima-se que a pesca amazônica envolve atualmente cerca de 230.000 pescadores, sendo a grande maioria moradores de várzea (Bayley \& Petrere 1989, Furtado 1990). O terceiro fator é a expansão da pecuária bubalina e bovina que aproveita os campos naturais da várzea ${ }^{1}$. A expansão da pecuária extensiva tem contribuído para o desmatamento de florestas de várzea e para a sobreexploração dos campos naturais, modificando significativamente os ambientes de várzea e contribuindo para a diminuição da capacidade produtiva dos ecossistemas aquáticos (Goulding 1996).

Enquanto os estoques pesqueiros ainda não estão sobreexplorados, o aumento do esforço pesqueiro tem reduzido consideravelmente a produtividade do esforço da pesca artesanal (Bayley \& Petrere, 1989). Preocupados com o declínio da produtividade pesqueira, comunidades ribeirinhas têm tentado proibir a entrada de pescadores comerciais de fora nos lagos locais. Como resultado dessas ações, conflitos entre comunidades e pescadores comerciais de fora têm se proliferado em toda a bacia, fazendo vítimas e levando à destruição de apetrechos, barcos (Hartman, 1984, Junk, 1984b and McGrath et al. 1993a). Até o momento, o Estado tem mostrado-se incapaz de efetivamente monitorar e gerenciar o recurso pesqueiro ou de mediar os conflitos entre comunidades ribeirinhas e pescadores comerciais. Enquanto a atual legislação pesqueira for bastante abrangente, com exceção da pesca industrial do estuário, um regime de livre acesso prevalecerá, incentivando os pescadores a explorar o recurso sem se preocupar em manter sua produtividade a longo prazo.

Os esforços das comunidades ribeirinhas em assumir o controle de lagos locais representam uma tentativa de preencher o vazio deixado pela ausência do controle do Estado. Em toda a região, comunidades, freqüentemente com o apoio de associações de pescadores como a Colônia de Pescadores e de organizações religiosas como a CPP (Comissão Pastoral da Pesca) e CPT (Comissão Pastoral da Terra) estão controlando os lagos locais e criando reservas de lago nas quais a comunidade define e implementa medidas, regulamentando a pesca nos seus lagos (CPT 1992a \& b, McGrath et al. 1993a, 1993b, 1994, Pinedo Vasquez et al. 1992, Lima 1994). Dada a discrepância entre tamanho e complexidade ecológica da várzea amazônica

1 Isso é a situação na várzea abaixo de Manaus, talvez ainda não seja o caso na várzea do rio Solimões. 
e os recursos limitados do IBAMA, é essencial a participação efetiva dos usuários no manejo dos recursos pesqueiros locais, se o controle do manejo for estendido ao nível local. Neste contexto, os esforços das comunidades ribeirinhas em administrar a pesca local representam uma alternativa promissora para o desenvolvimento sustentável da pesca na Amazônia.

\section{Modelos de manejo para o desenvolvimento da pesca na Amazônia brasileira}

O recurso pesqueiro da várzea pode ser caracterizado como um "recurso comum" definido segundo Feeny et al. (1990), como uma classe de recursos para os quais é difícil excluir outros (exclusividade) e para os quais o uso por um indivíduo reduz a quantidade disponível para outros usuários (subtrabilidade). Pesquisadores freqüentemente distinguem quatro regimes de propriedade sobre os quais os recursos comuns podem ser manejados: livre acesso, propriedade comum, propriedade privada e propriedade estatal (Bromley \& Cernea, 1989, Feeny et al. 1990).

O regime de livre acesso é caracterizado pela ausência de regras. O acesso ao recurso não é regularizado e qualquer um tem o direito de explorá-lo. Este regime freqüentemente tem sido confundido com o regime de propriedade comum como no trabalho clássico de Hardin (1968), "A Tragédia dos Comuns" no qual ele usa o termo comuns para referir a um regime de livre acesso (Feeny et al. 1990). Em contraste ao livre acesso, num regime de propriedade comum os direitos sobre os recursos são mantidos por um grupo distinto de usuários que exclui pessoas de fora e regulamenta o uso entre si. Normalmente, os usuários têm acesso e uso igualitário ao recurso. Estes direitos comunitários podem ser ou não reconhecidos formalmente pelo Estado.

Hardin (1968) desconsiderou o regime de propriedade comum e argumentou que a solução para a destruição ambiental causada pelo livre acesso era a conversão do sistema em propriedade privada ou estatal. No regime de propriedade privada, indivíduos têm o direito de excluir outros e regulamentar o uso do recurso. Os direitos aos recursos são transferíveis e normalmente são reconhecidos e apoiados pelo Estado. No regime de propriedade estatal, os direitos de acesso e de uso pertencem exclusivamente ao Estado. O Estado pode ceder o acesso e o uso para indivíduos, enquanto em outros, o Estado pode permitir acesso para todos, mas regulamenta o uso do recurso.

Em graus diferentes, todos os quatro modelos estão sendo operados na pesca amazônica. A política pesqueira oficial é baseada no regime de propriedade estatal. Entretanto, o desenvolvimento do manejo comunitário é mais consistente com o regime de propriedade comum. Ao mesmo tempo, a presença limitada do Estado no interior tem levado a uma situação de livre acesso em grandes áreas de várzea, enquanto em outras áreas, como o leste da Ilha de Marajó, grandes proprietários têm tomado posse dos lagos estabelecendo um regime de propriedade privada de fato. Entretanto, nem o livre acesso nem o regime de propriedade privada são considerados opções de manejo legítimas à pesca na Amazônia, e o debate sobre a política de manejo pesqueiro tem enfocado formas de propriedade estatal e de propriedade comum, tratados aqui respectivamente como os Modelos Tecnocrata e Comunitário.

O Modelo Tecnocrata tem servido como base para o desenvolvimento pesqueiro no mundo inteiro (McGoodwin, 1990; McEvoy, 1990). Esse modelo tem como premissa fundamental que o recurso pertence à sociedade e que, portanto, o Estado tem a 
responsabilidade de manejar o recurso para aproveitar todos os benefícios que podem ser extraídos de forma sustentável. Conseqüentemente, o principal enfoque do Modelo Tecnocrata é a eficiência, mais especificamente na porcentagem do potencial produtivo do recurso que está sendo explorado. Uma outra premissa é que o nível ótimo de exploração possa ser definido cientificamente e políticas de manejo ajustadas para atingir este nível ótimo de captura (Larkin, 1977-1978; Nielsen, 1976). No decorrer deste século, tem-se acumulado uma grande quantidade de trabalhos teóricos e empíricos, sendo a maior parte relacionada com o desenvolvimento de modelos e metodologias para a determinação de níveis ótimos de captura (Anderson 1986, Scott 1979, Welcomme 1985).

No Modelo Tecnocrata, pescadores são tipicamente profissionais de período integral, que se deslocam entre diferentes locais de pesca no decorrer do ano. O Estado assume responsabilidade pelo manejo da pesca. A política de manejo é desenvolvida por oficiais do governo, com a participação variável de pesquisadores, de grupos organizados de pescadores e de indústrias, e é implementada pelos fiscais dos escritórios regionais. Os pescadores são motivados, por interesses próprios, a maximizar o valor de suas capturas, sem nenhuma motivação para conservar as populações locais de peixes, uma vez que eles sabem que os peixes deixados na água serão capturados por outros pescadores. Sendo assim, cabe ao Estado elaborar e implementar regras para assegurar que o nível de pressão não exceda a capacidade produtiva do recurso. Este modelo requer uma extensa infra-estrutura institucional em toda a região, a fim de monitorar e fiscalizar os pescadores, incluindo sofisticados programas de pesquisa para coletar dados básicos sobre a biologia, ecologia e economia pesqueira e de um sistema de patrulhas que monitorie e fiscalize a pesca nas principais regiões onde ocorrem as capturas.

O Modelo Comunitário de manejo pesqueiro tem sido foco de bastante atenção nos últimos quinze anos, especialmente entre antropólogos e outros cientistas sociais (McCay \& Acheson, 1987; Berkes, 1989; Chernela, 1985; Cordell \& McKean, 1986; Stocks, 1987; McGoodwin, 1990). Embora desprezado durante muito tempo por não ser científico e, portanto, incapaz de aproveitar o potencial produtivo do recurso pesqueiro, o Modelo Comunitário está ganhando respeito entre pesquisadores e administradores de pesca, principalmente devido à crise que muitas regiões pesqueiras estão enfrentando (McGoodwin, 1990; Fairlie et al. 1994; Mathews, 1994). Nesse modelo, um grupo específico de pescadores, membros de uma ou mais comunidades, ou de alguma organização coletiva, controla o acesso e o uso de um território pesqueiro bem definido. Pescadores são sedentários, visto que eles são limitados a um território definido. Regras regulando o uso do recurso pesqueiro são definidas por membros da comunidade ou do grupo de usuários local, com níveis variados de participação de outras organizações/instituições. A fiscalização é principalmente uma responsabilidade da comunidade ou dos membros do grupo de usuários local. A organização comunitária normalmente recebe pelo menos um apoio do órgão governamental local responsável pelo manejo pesqueiro.

\section{Políticas de manejo pesqueiro na Amazônia brasileira}

O manejo pesqueiro na Amazônia brasileira segue o Modelo Tecnocrata. O IBAMA (Instituto Brasileiro de Meio Ambiente e Recursos Naturais Renováveis) é o órgão responsável pelo gerenciamento pesqueiro dessa área. Pela legislação brasileira, as águas interiores pertencem ao Estado, e o pescador tem o direito de pescar em qualquer lugar que ele possa alcançar por barco. Proprietários de corpos d'água são formalmente reconhecidos somente em 
casos de lagos isolados permanentemente e lagoas que são totalmente cercadas por propriedades privadas. As políticas de manejo são definidas por tecnocratas do IBAMA com a participação de pesquisadores e representantes de organizações de pescadores e de indústrias. Enquanto o escritório regional do IBAMA possui alguma flexibilidade em adaptar regulamentações para as condições locais, todas as principais decisões de gerenciamento devem ser formalizadas em portarias assinadas pelo presidente do IBAMA. Esse condicionamento configura-se num dos principais obstáculos à habilidade do IBAMA em administrar questões sobre o manejo local.

A política pesqueira brasileira utiliza toda a gama de ferramentas do manejo convencional, incluindo restrições sobre tipos de apetrechos de pesca, requerimentos de tamanho mínimo, e proibições durante o período de desova (Isaac et al. 1993). Em alguns Estados da Amazônia, arrastões e redes de lancear são proibidos em águas interiores e somente malhadeiras fixas e flutuantes são permitidas. A pesca é proibida para algumas espécies durante os três meses de desova. Também são especificados tamanhos mínimos para algumas espécies comercialmente importantes. Com exceção de parques e outros tipos de reservas biológicas, existem poucas restrições territoriais, o acesso às áreas inundadas da várzea é teoricamente permitido aos pescadores o ano todo. Apesar das licenças de pesca serem obrigatórias para todos os pescadores comerciais, com exceção da pesca industrial no estuário, não existem restrições sobre o número de pescadores que podem explorar o recurso pesqueiro, e aqueles que pescam sem uma licença oficial raramente são punidos. Portanto, para todos os propósitos e intenções, a pesca amazônica é de livre acesso.

Como foi mencionado anteriormente, o Modelo Tecnocrata concentra no Estado a capacidade de monitorar os estoques pesqueiros e a fiscalização da atividade da pesca. A implementação efetiva desse modelo é difícil em áreas onde a ecologia pesqueira é muito mais simples e melhor entendida que na Amazônia (McGoodwin, 1990; Fairlie et al. 1994). O IBAMA não possui os recursos humanos, os fundos ou os equipamentos necessários para implementar esse modelo. Não existe, por exemplo, registros oficiais que forneçam estimativas confiáveis do número de embarcações de pesca atuando na região. Além disso, o monitoramento dos mercados de peixe nos maiores centros urbanos é mínimo e, nas áreas rurais, o IBAMA é incapaz de fiscalizar a pesca e os estoques pesqueiros de forma eficaz. Somente na última década, grupos de pesquisa, colaborando com o IBAMA, têm desenvolvido programas para monitorar o desembarque de peixes nos maiores centros urbanos. $\mathrm{O}$ resultado é que a atividade de pesca é regulada mais pelas condições naturais do que pelo Estado (Goulding 1983).

\section{Manejo comunitário de lagos: um modelo em evolução}

O modelo de reserva de lago que está sendo desenvolvido na Amazônia é baseado no Modelo Comunitário descrito acima (McGrath et al. 1993b, 1994). Aqui, em vez de considerar a várzea como uma única unidade de manejo na qual pescadores circulam livremente, o manejo pesqueiro está organizado em torno de sistemas de lagos e das populações locais. Neste modelo, pescadores são normalmente sedentários, pescando nos lagos mais próximos de sua comunidade. Enquanto os pescadores são também considerados atores preocupados com seus próprios interesses, existem, neste caso, mecanismos para proteger e reconciliar os interesses individuais e coletivos. Nesse sentido, o surgimento do modelo de reserva de lago tem potencial para satisfazer as condições básicas necessárias ao manejo coletivo: um território dis- 
tinto controlado por um grupo de usuários bem definidos com acesso exclusivo ao recurso (Ostrom, 1990; McCay \& Acheson, 1987).

Embora a reserva de lago seja um fato relativamente recente, ele está baseado em noções tradicionais de ecologia pesqueira e posse de terra. Até certo ponto, a noção de posse de lago está relacionada com a maneira como as propriedades individuais são definidas. A propriedade na várzea é geralmente definida, não em termos de sua área, mas em termos de seu comprimento ao longo do rio ou Paraná (metros de frente). $\mathrm{Na}$ maoria das vezes, a propriedade se estende da margem do rio até o centro da ilha ou lago, onde se encontram propriedades que se estendem para o centro do outro lado da ilha. Um resultado prático é a dificuldade em saber a área total de uma propriedade individual porque o fundo das propriedades é apenas vagamente estimado.

Embora vago em termos de área, este sistema fundiário fornece a cada proprietário o acesso a todos os principais ambientes da várzea (veja Denevan, 1984). O rio é utilizado como meio de transporte e sazonalmente para a pesca. As habitações são localizadas na terra alta das restingas beirando os rios e canais, e é nesse local que a maioria das atividades agrícolas são desenvolvidas. A pecuária é praticada nos campos naturais na zona de transição entre o lago e a restinga, e na maior parte do ano, a pesca se concentra nos lagos.

Apesar das propriedades individuais incorporarem os principais hábitats da várzea, estas zonas ecológicas são tratadas diferentemente dentro do sistema de posse da terra. Existe um gradiente de uso individual da beira do rio até o lago ${ }^{2}$ (Fig. 2). Ao longo deste transecto, a restinga é considerada propriedade privada com limites claramente definidos e, muitas vezes, é cercada. Em geral, os campos naturais atrás da restinga são considerados como área comum. É permitido ao gado circular livremente nesta zona, ainda que proprietários individuais tenham o direito de cercar as áreas de campo dentro de sua propriedade. O lago é considerado também uma propriedade comum e às tentativas de restringir acesso aos lagos são resistidas se o lago não estiver inteiramente dentro de uma ou algumas propriedades. Então, a maior diferença, em termos fundiários, está entre a restinga, que é explorada individualmente, e os campos inundados e os lagos, que são tratados como comuns. De certa forma, a posse da margem do rio fornece acesso ao campo e lago do interior da várzea.

Seguindo esta lógica, a posse ou o controle dos lagos pela comunidade é normalmente baseado na posse da terra ao redor do lago pelos membros da comunidade, embora o uso tradicional por comunidades vizinhas possa também ser reconhecido. Neste sistema, a comunidade, como um proprietário coletivo, é dona do pescado no lago, do mesmo modo que um proprietário de terra firme reivindicaria a posse da caça em sua propriedade. Esta perspectiva da pesca nos lagos fornece a base para o manejo coletivo do recurso, uma vez que fica definido o grupo de indivíduos que tem acesso ao recurso e se beneficia dele.

\subsection{Objetivos e medidas de manejo}

O manejo comunitário da pesca é baseado em acordos comunitários denominados "acordos de pesca" que especificam as medidas a serem tomadas e as sanções a serem usadas

\footnotetext{
2 O rio que passa na frente das casas é considerado mais ou menos de livre acesso, embora os moradores freqüentemente reivindiquem o direito de proibir atividades que aconteçam em frente a suas propriedades, se essas atividades forem consideradas prejudiciais aos seus interesses.
} 
contra infratores. Em geral, estes documentos são elaborados em reuniões comunitárias e assinados pelos presentes que estão em concordância. O documento então é escrito em forma de petição, com as assinaturas anexadas, e é apresentado ao IBAMA, à Colônia de Pescadores e às autoridades municipais para o reconhecimento formal. Entretanto, este reconhecimento não implica em apoio legal, mas serve para legitimar o acordo aos olhos da comunidade, provendo apoio moral, se não legal, para as ações de fiscalização dos acordos.

O principal objetivo dos acordos de pesca é estabilizar ou reduzir a pressão sobre os recursos pesqueiros locais. Esses acordos normalmente tentam atingir esse objetivo indiretamente através de restrições aos apetrechos de pesca e à capacidade de armazenamento, em vez de delimitar diretamente o tamanho da captura. Além de regular a atividade pesqueira, acordos de pesca freqüentemente incluem medidas que pretendem conservar hábitats considerados importantes para a população de peixes do lago. Eles podem também incluir medidas traçadas para regular a exploração de outras espécies, como quelônios ${ }^{3}$. Estes acordos tipicamente incluem algumas das seguintes medidas.

1) Acesso ao Recurso Pesqueiro. A medida mais comum é proibir os pescadores, que não fazem parte da comunidade, de entrarem nos lagos. Onde a pesca é principalmente orientada para a subsistência, esta medida é suficiente para restaurar ou manter a produtividade da pesca. Quando a maioria dos pescadores comercializam sua captura, esta medida dificilmente é suficiente para manter a produtividade.

2) Mercado pesqueiro. Uma das formas mais fáceis de controlar a pressão sobre o recurso pesqueiro é restringir a comercialização da captura. Em alguns casos, a pesca comercial é totalmente proibida, enquanto em outros é restrita a certas espécies ou grupos de espécies, ou ainda a determinado período do ano. Há casos em que a comercialização do pescado é permitida somente dentro da comunidade, limitando a captura total às necessidades da comunidade como um todo.

3) Apetrechos de pesca. As comunidades freqüentemente proíbem o uso de um ou mais tipos de apetrechos durante todo ou parte do ano. O principal alvo dessa medida é a malhadeira, que é considerada a principal causa da pressão excessiva sobre os recursos dos lagos. Restringir o uso da malhadeira é considerada a forma mais efetiva de limitar o tamanho da captura. As malhadeiras podem ser permanentemente proibidas (freqüentemente no caso da pesca de subsistência) ou durante parte do ano, normalmente na estação seca, quando os peixes estão concentrados em pequenos corpos d'água. Além disso, acordos de pesca também podem proibir uma gama de tipos de apetrechos e técnicas de pesca, incluindo arrastões e redes de lancear, os quais podem ou não ser ilegais em alguns Estados amazônicos.

4) Armazenamento. Uma outra maneira de restringir o tamanho da captura é limitar a capacidade de armazenamento. Existem várias medidas que comunidades podem adotar. Primeiro, a comunidade pode criar restrições sobre o tamanho ou o tipo de embarcação (barco a motor, por exemplo) que pode entrar no lago. Segundo, pode limitar o tamanho das caixas de isopor usadas para armazenar o pescado. Finalmente, pode proibir gelo e permitir somente o sal, a forma tradicional de preservar o pescado.

\footnotetext{
3 Estas medidas podem ser ou não consistentes com a atual legislação pesqueira.
} 
5) Conservação de Hábitat. Os pescadores possuem um conhecimento íntimo da relação entre a vegetação dos lagos e a sua produtividade pesqueira, e muitas comunidades definem medidas para proteger a vegetação considerada importante para a pesca local. Alguns acordos de pesca, por exemplo, especificam regras para preservar a cobertura de macrófitas flutuantes e proteger árvores frutíferas durante a época da cheia. Em toda região de várzea, os pescadores reclamam dos efeitos prejudiciais do búfalo nos ambientes aquáticos, e em alguns casos, comunidades têm proibido a criação de búfalos na área da comunidade.

6) Zoneamento de Sistemas de Lagos. Os lagos de várzea são na realidade sistemas de lagos que sofrem grandes mudanças físicas e ecológicas. Em certos casos, comunidades distinguem diferentes tipos de lagos e adaptam regras de pesca às características de cada tipo. Por exemplo, pescadores diferenciam lagos rasos e sazonais, que podem secar na estação de águas baixas, e lagos profundos e permanentes, muitas vezes chamados de "lagos de criação", onde os peixes tendem a se concentrar durante a estação seca. A pesca comercial pode ser permitida em lagos rasos durante a estação seca, uma vez que os peixes nesses lagos podem morrer de qualquer modo, enquanto em lagos mais profundos a pesca pode ser restrita às necessidades de subsistência ou totalmente proibida durante a estação seca.

7) Organização Coletiva e Fiscalização. Este é o aspecto mais problemático do manejo comunitário de lago. Os acordos são geralmente vagos com relação aos aspectos organizacionais do manejo coletivo. Geralmente a responsabilidade pela fiscalização das medidas fica sob os cuidados da liderança local da Colônia de Pescadores ou sob outros líderes comunitários. Como acordos de pesca não têm legitimidade formal, os indivíduos responsáveis pela organização do manejo coletivo não possuem a autoridade legal para fiscalizar medidas comunitárias.

Acordos de pesca freqüentemente especificam sanções gradativas a serem impostas aos infratores. Na primeira vez o infrator pode receber um aviso; na segunda vez, suas malhadeiras podem ser confiscadas por um período ou o pescador pode ser multado; e na terceira, seus apetrechos podem ser confiscados e destruídos. Algumas vezes, os apetrechos confiscados são levados ao IBAMA ou à Colônia, e uma queixa formal é feita contra o indivíduo ou grupo de infratores. Essa ação é simbólica e serve mais para legitimar ações da comunidade do que para punir infratores, uma vez que o IBAMA raramente toma alguma atitude decisiva. Enquanto as punições aos infratores das regras comunitárias são, freqüentemente especificadas, os mecanismos de fiscalização raramente são. Embora algumas comunidades façam patrulhas noturnas esporádicas para descobrir pescadores ilegais, a maioria parece depender da descoberta por acaso por membros da comunidade.

\subsection{A lógica do manejo comunitário}

O modelo comunitário é baseado na lógica da economia do pequeno produtor da várzea. Pescadores artesanais e de subsistência são tipicamente de tempo parcial, sendo a pesca apenas uma das atividades que contribuem para a economia familiar. Conseqüentemente, pescadores têm tempo limitado para se dedicar à pesca e preferem uma pesca de produtividade relativamente alta, onde eles possam capturar a quantidade necessária com um investimento de tempo mínimo. Pescadores artesanais estão, em efeito, trocando produção por produtividade. Isto é evidente na Tabela 1 onde são apresentados os resultados de um estudo comparando a produtividade da pesca em lagos manejados e não manejados (McGrath et al. 1994). No primeiro caso, o manejo é orientado para subsistência, embora a pesca comercial seja permitida 
para algumas espécies durante uma época do ano. No segundo caso, a pesca comercial domina e existe pouco controle sobre a atividade pesqueira. Na comparação da atividade pesqueira, destaca-se a troca, feita pela comunidade do lago Manejado da produção pela produtividade. A produtividade da pesca no lago Manejado foi $30 \%$ mais alta e a produção pesqueira foi $30 \%$ mais baixa que no lago Não Manejado.

A pescaria de alta produtividade requerida por pescadores artesanais e pequenos produtores contribui para a produção global da família de várias maneiras. A pesca fornece uma fonte regular de proteína animal para a subsistência da família. A venda do pescado fornece uma renda para comprar as necessidades básicas da família durante o período de cultivo agrícola, enquanto qualquer renda excedente pode ser utilizada para pagar mão-de-obra, sementes e outros insumos agrícolas. Como os pescadores da várzea dizem: "dois dias pescando e um dia plantando".

Tabela 1: Produtividade de mão-de-obra em lagos manejados e não manejados

\begin{tabular}{|c|c|c|}
\hline \multicolumn{3}{|c|}{ Regime de Manejo } \\
\hline Atividade & Manejado & Não Manejado \\
\hline \multicolumn{3}{|c|}{ Renda Familiar Anual: } \\
\hline Pesca & $\mathrm{R} \$ 600$ & $\mathrm{R} \$ 950$ \\
\hline Agricultura & $\mathrm{R} \$ 350$ & 0 \\
\hline Total & $\mathrm{R} \$ 950$ & $\mathrm{R} \$ 950$ \\
\hline \multicolumn{3}{|c|}{ Produtividade de Trabalho (R $\$ /$ pessoa/hora) } \\
\hline Pesca & $\mathrm{R} \$ 1.16$ & $\mathrm{R} \$ 0.94$ \\
\hline Agricultura & $\mathrm{R} \$ 0.74$ & \\
\hline Combinada & $\mathrm{R} \$ 1.03$ & $\mathrm{R} \$ 0.94$ \\
\hline
\end{tabular}

Fonte: McGrath et al. (1994).

Apesar da produtividade do trabalho agrícola ser consideravelmente mais baixa do que da pesca, a diferença é compensada no lago Manejado pela alta produtividade da mão-de-obra na pesca. Como resultado, a produtividade do trabalho combinado no lago Manejado é $10 \%$ maior do que a pesca no lago Não Manejado (Tabela 1). A economia familiar no lago Manejado também é mais diversificada, com um terço da renda total proveniente da agricultura. Além disso, como a captura total é limitada por regras comunitárias, o sistema como um todo é teoricamente sustentável, uma hipótese que não pode ser sustentada para a pesca no lago Não Manejado.

O exemplo ilustra as contribuições da alta produtividade da pesca e da diversificação econômica para a maior eficiência de produção no Modelo Comunitário. A pesca e a agricultura são interdependentes no Modelo Comunitário. A alta produtividade da pesca no lago Manejado é possibilitada pela diminuição na captura total, que é viabilizada pela renda derivada da agricultura. Como a pesca é uma atividade extrativista, qualquer tentativa de aumentar a renda além dos níveis atuais (com a tecnologia existente) conduzirá a um declínio na produtividade de trabalho na pesca abaixo dos níveis verificados no sistema diversificado. Então, a maior produtividade da pesca, essencial para o Modelo Comunitário, é atingida através da diversificação da economia familiar, combinando uma atividade extrativista de alta produtividade com atividades produtivas de baixa produtividade tais como a agricultura e a criação de pequenos animais. O resultado é um equilíbrio dinâmico entre pesca e agricultura, extração e produção, que é mantida pela fiscalização dos acordos de pesca comunitária (Hecht et al. 1988). 


\section{O manejo pesqueiro e o desenvolvimento rural na várzea}

$\mathrm{Na}$ seção anterior descrevemos os dois modelos de manejo que estão surgindo com o desenvolvimento da pesca comercial na Amazônia. Nesta seção, avaliamos o potencial desses modelos com relação às duas questões abordadas: 1) a efetividade relativa dos dois modelos para o manejo da pesca na várzea, e 2) os impactos de cada modelo no processo de desenvolvimento da várzea.

\subsection{Lagos de várzea como unidades de manejo da pesca e de outros recursos naturais}

Talvez, a primeira questão para avaliar o potencial de reservas comunitárias de lago comunitárias seja: até que ponto um sistema individual de lagos de várzea constitui uma unidade de manejo efetivo para a pesca amazônica e para o conjunto de recursos da várzea. Lagos de várzea são sistemas abertos, componentes de um sistema fluvial imenso e altamente dinâmico que abrange cerca de 40\% do continente sul-americano Junk, 1984b; Junk et al. 1989; Goulding, 1989; Welcomme, 1985). Durante metade do ano, lagos individuais desaparecem com a inundação da várzea pelo rio, formando um imenso lago de 50 a 100 quilômetros de largura e mais de quatro mil quilômetros de comprimento (Fig. 3). Nesta época, somente a copa das árvores e casas sobre palafitas permanecem visíveis indicando os contornos dos lagos individuais. Durante a outra metade do ano a inundação recua e expõe centenas de milhares de corpos d'água que variam de meros poços até lagos de dezenas de quilômetros de diâmetro (Fig. 3). Ao mesmo tempo, peixes são móveis, com o potencial de se deslocarem de lago para lago no decorrer do ano.

Dado essas características dos sistemas de lagos da várzea, não fica totalmente claro que exista alguma relação duradoura entre uma determinada população de peixes e o lago em que se encontra essa população. Se o peixe circula entre os lagos de toda a extensão da várzea, não há razão para esperar que a política de manejo aplicada em um dado lago tenha um efeito duradouro no sistema como um todo. Por exemplo, um lago despescado durante a estação seca pode ser simplesmente recolonizado na estação da enchente. Se estas condições prevalecem, então o modelo itinerante poderá ser a estratégia de manejo mais apropriada, desde que os pescadores possam seguir as populações de peixes circulando entre os sistemas de lagos. Alguma variação do regime de manejo de pesca proposto por Bayley (1995b) talvez poderá ser a forma mais apropriada para o manejo pesqueiro dos lagos.

Entretanto, os resultados do estudo comparativo citado acima sugerem que o regime de manejo pode ter efeito duradouro sobre a produtividade da pesca nos lagos (Tabela 1). As diferenças na produtividade global da pesca são difíceis de avaliar. Quando controlamos os tipos de apetrechos, a produtividade no lago Manejado é duas vezes maior do que no lago Não Manejado (McGrath et al. 1994). Este é um resultado preliminar e não foi possível controlar os fatores ambientais que poderiam ser responsáveis por toda ou parte dessa diferença em produtividade. Contudo, os resultados são consistentes, se considerada a avaliação dos pescadores que atuam no lago Manejado. A comunidade decidiu proibir o uso de malhadeiras e a pesca comercial em geral, em resposta ao rápido declínio na produtividade dos lagos causado pela pressão excessiva da pesca comercial. Desde que o regime de manejo de subsistência foi implantado, a produtividade da pesca no lago tem aumentado significativamente, indicando que os efeitos de práticas locais de manejo perduram além da estação anual da enchente. 
Enquanto este estudo sugere que sistemas individuais de lagos são unidades de manejo potencialmente viáveis para a pesca nos lagos de várzea, até que ponto eles podem servir como unidades de manejo varia de espécie para espécie, dependendo do comportamento migratório e reprodutivo da espécie, e da importância dos lagos de várzea para aquela espécie. Por exemplo, lagos manejados serão mais favoráveis para espécies tais como pirarucu (Arapaima gigas) e tucunaré (Cichla spp.) que reproduzem em lagos e não fazem migrações anuais de longa distância. Isto é confirmado pela comparação da pesca de pirarucu no lago Manejado e Não Manejado. A produção de pirarucu no lago Manejado, onde a pesca desse peixe é permitida durante somente seis meses, foi o dobro do lago Não Manejado onde a pesca de pirarucu é praticada o ano todo sem restrições efetivas (McGrath et al. 1994). Seguindo este mesmo raciocínio, o manejo de lagos individuais é provavelmente menos positivo para espécies de médio migradores tais como o tambaqui (Colossoma macropomum) que realizam migrações sazonais e se reproduzem em rios. Embora provavelmente irrelevante para migradores de longa distância como a dourada (Brachyplatystoma flavicans) e a piramutaba (Brachyplatystoma vaillantii), um sistema regional de reservas de lago estendendo-se ao longo de toda a várzea amazônica, poderia ajudar a proteger migradores de média distância na maior parte de seu território, e forneceria também centros locais para repovoar os lagos vizinhos (Barthem \& Petrere 1991, Goulding 1980).

O segundo ponto em relação ao papel de reservas de lago como unidade de manejo é o seu potencial para manejar outras espécies da várzea. A esse respeito, um dos aspectos mais importantes da reserva de lago é a integração simultânea dos principais componentes do ecossistema de várzea e os principais recursos e atividades econômicas da região ribeirinha (Fig. 4). Os três principais ambientes da várzea, a floresta da restinga, os campos inundados, e os lagos e canais permanentes são também os focos das principais atividades econômicas da várzea. As comunidades ribeirinhas estão localizadas nas restingas, onde são realizadas a maioria das atividades agrícolas, enquanto a pecuária é praticada nos campos sazonalmente inundados. A maior parte das atividades de pesca na várzea está voltada para os lagos ao invés do rio. A pesca, então, é apenas uma parte do complexo de atividades que explora os principais hábitats da várzea. Como a produtividade da pesca de várzea é intimamente associada ao status dos hábitats dos lagos, a reserva de lago internaliza muitas das conseqüências positivas e negativas das práticas locais de uso do solo. Como um modelo de manejo, a reserva de lago, então, fornece uma estrutura para avaliar os impactos de atividades individuais sobre outros componentes do sistema de reserva de lagos, e dessa maneira facilita o desenvolvimento de sistemas de manejo que levam em conta as complexas interações entre recursos naturais, hábitats e atividades econômicas (Junk, 1989; Bayley, 1995a; Goulding, 1993-1996; Sparks, 1995).

\subsection{Recursos pesqueiros e desenvolvimento rural}

O principal tema deste trabalho é a pesca como recurso estratégico da várzea. $O$ recurso pesqueiro é crítico não só para a viabilidade econômica do pequeno produtor varzeiro, mas como um recurso altamente produtivo e renovável, capaz de gerar um fluxo amplo e contínuo de benefícios econômicos para aqueles que estão em posição de aproveitá-lo. Assim, quem têm controle do recurso pesqueiro e a forma como o recurso é explorado terá profundas conseqüências para o processo de desenvolvimento da várzea. Os dois modelos de manejo descritos aqui oferecem fundamentalmente diferentes estratégias para o desenvolvimento da pesca, e provavelmente irão resultar em efeitos muito diferentes, não apenas para a pesca, mas também para o povoamento e uso do solo da várzea. Esses diferentes cenários são resumidos 
nas Figuras 5a e b. A Figura 5a é uma representação esquemática da provável trajetória de desenvolvimento sob o Modelo Tecnocrata e a Figura 5b é a trajetória potencial de desenvolvimento do Modelo Comunitário caso fosse implementado com sucesso. Deve ser notado que os dois cenários apresentados aqui não pretendem representar os dois únicos caminhos possíveis para o desenvolvimento da várzea, mas sim os dois extremos de uma gama de possibilidades que dependerão das medidas políticas adotadas, das condições locais, e da maneira como essas políticas são implementadas.

\subsection{Modelo tecnocrata}

Desenvolvimento pesqueiro implica transformar o setor pesqueiro. Da perspectiva do Modelo Tecnocrata a pesca artesanal é ineficiente. A sua pequena escala e tecnologia limitada e o fato de ser praticada tipicamente por pescadores de tempo parcial, limitam a capacidade da pesca artesanal de explorar de forma eficiente o potencial produtivo do recurso. A solução da perspectiva do Modelo Tecnocrata é modernizar o setor pesqueiro, aumentando a capacidade dos barcos pesqueiros e transformando os pescadores artesanais em profissionais de tempo integral (McGoodwin, 1990).

$\mathrm{Na}$ Amazônia, uma política de livre acesso combinada com programas para modernizar a frota comercial teria o efeito de direcionar o acesso à pesca de várzea a um grupo relativamente pequeno de pescadores profissionais itinerantes, preparados para se beneficiarem de programas governamentais de crédito subsidiado (Cordell \& McKean, 1986). Através de investimentos para ampliar a capacidade da frota, a captura total aumentaria, sendo que o setor moderno será responsável pela maior parte desse crescimento. Dessa maneira o setor moderno obteria uma proporção crescente do valor total apropriado do recurso. Esse aumento viria aos custos do setor artesanal que, sem condições para aumentar seu esforço de captura, veria a redução de sua parte na captura total.

Essa tendência teria conseqüências devastadoras para os pescadores artesanais. Com o declínio da produtividade do esforço no setor pesqueiro artesanal, a renda proveniente da pesca também entraria em declínio. Pequenos produtores rurais, para os quais a pesca é um componente básico da economia familiar, encontrariam-se em uma situação cada vez mais difícil (Kurien 1994). Sem alternativas viáveis para substituir a renda perdida, ficaria cada vez mais difícil a permanência na várzea. Os pequenos produtores rurais responderiam a essa situação tentando proibir a entrada de pescadores de fora nos lagos locais, resultando na proliferação dos conflitos de pesca (CPT, 1992a). Portanto, com a política do governo apoiando livre acesso, os pescadores artesanais dificilmente conseguiriam fechar os lagos. Como resultado, mais e mais pequenos produtores venderiam suas terras para fazendeiros vizinhos e deslocariam-se para as colônias da terra firme ou para os centros urbanos regionais, aumentando a população pobre das periferias urbanas (McCully, 1991; Furtado, 1990; McGrath et al. 1993a).

Essa tendência seria reforçada pelo fato de que pescadores do setor moderno investem seus lucros da pesca na pecuária, geralmente vista como um dos investimentos mais seguros e de maior liquidez disponíveis (Hecht, 1993; Mattos \& Uhl, 1994). Através desse mecanismo, o excedente proveniente da pesca é transferido para a pecuária, contribuindo diretamente para a expansão da pecuária na várzea. Como os campos da várzea são tratados como campos de livre acesso, existe incentivo para sua sobreexploração. Esse uso excessivo combinado com a queimada sazonal dos campos e a derrubada das florestas de várzea remanescente, resultaria na 
degradação progressiva dos ecossistemas de várzea, reduzindo a capacidade produtiva do recurso pesqueiro. Ao mesmo tempo, por causa da incapacidade do IBAMA de monitorar de forma adequada os estoques pesqueiros e fiscalizar a atividade pesqueira, esse órgão não poderia evitar a sobrepesca e a eventual exaustão dos estoques pesqueiros. Dessa maneira, a pesca seria pressionada de dois lados: a degradação dos hábitats de um lado e uma pressão pesqueira sem controle do outro.

Existe, então, uma forte probabilidade de que, se a política pesqueira seguir o Modelo Tecnocrata, o desenvolvimento da pesca terá conseqüências profundamente negativas para as populações e ecossistemas da várzea. Em vez de desencadear um processo de desenvolvimento rural, é provável que o desenvolvimento da pesca resulte no empobrecimento dos pequenos produtores varzeiros, exaustão do recurso pesqueiro e a degradação dos ecossistemas de várzea. O ponto principal aqui, entretanto, é que mesmo se o desenvolvimento pesqueiro fosse bem-sucedido no sentido de aumentar a captura total sem esgotar os estoques, as conseqüências para os pequenos produtores seriam as mesmas. Esta observação também vale para a degradação ambiental resultante da expansão da pecuária, incentivada direta e indiretamente pelo desenvolvimento da pesca.

\subsection{O modelo de manejo comunitário}

No Modelo de Manejo Comunitário, a política de desenvolvimento do governo direcionaria o acesso à pesca aos pequenos produtores de várzea (Fig. b). Aqui comunidades e organizações de pescadores seriam responsáveis pelo gerenciamento local dos recursos pesqueiros da várzea dentro do contexto de um programa regional de desenvolvimento da pesca. Organizadas como cooperativas ou associações comunitárias, essas organizações locais assumiriam responsabilidade do manejo da pesca nos lagos e da comercialização da captura. Políticas governamentais de desenvolvimento pesqueiro seriam orientadas para aumentar a eficiência do manejo local. Com o controle formal sobre a pesca local e organizações efetivas de manejo, pescadores teriam o incentivo para investir no manejo da pesca a longo prazo (MacKenzie, 1992).

Nesse modelo, programas governamentais de desenvolvimento seriam orientados para aumentar a produtividade da pequena produção varzeira e o fortalecimento da capacidade organizacional. Primeiro, seguindo a lógica da economia do pequeno produtor, programas de extensão incentivariam pequenos produtores a investirem sua renda de pesca em atividades produtivas como sistemas anuais intensivos, sistemas agroflorestais, a pequena criação, e especialmente sistemas integrados envolvendo espécies aquáticas e terrestres. Com a capitalização dos pequenos produtores, o crescimento da renda familiar viria cada vez mais de atividades produtivas em vez da pesca. Segundo, extensionistas do governo trabalhariam com grupos de pequenos produtores a fim de criar organizações coletivas para manejar a pesca e comercializar a produção. Através dessas organizações, comunidades poderiam investir na infra-estrutura local: energia elétrica, água tratada, transporte mais adequado, e até em melhorias na qualidade de educação e serviços de saúde, todas as necessidades rurais que governos municipais têm se mostrado incapazes de atender de forma adequada e consistente.

Dessa maneira, o Modelo Comunitário fornece um mecanismo através do qual o desenvolvimento da pesca financia diretamente a acumulação de recursos por pequenos produtores da várzea. Neste Modelo, a pesca de alta produtividade funciona como uma forma de crédito rural, mas com diferenças importantes. É muito mais eficiente do que programas 
convencionais de crédito porque não necessita de uma burocracia governamental para administrá-lo, nem precisa de documentos que produtores raramente têm, fornece crédito quando produtores precisassem dele, e como não precisa ser reembolsado, não absorve a maior parte da renda proveniente da venda da safra. Além disso, como a pesca é potencialmente um recurso renovável, o programa pode continuar indefinidamente sem ônus para o Estado.

Em resumo, no Modelo Comunitário, o desenvolvimento pesqueiro, em vez de tirar o recurso dos pequenos produtores, procura aumentar a eficiência com que a pesca local é explorada. Em contraste com o Modelo Tecnocrata em que a renda do pequeno produtor cai, o desenvolvimento pesqueiro, seguindo o Modelo Comunitário, poderia contribuir para a capitalização da pequena produção. Ao mesmo tempo, o aumento da renda familiar com o desenvolvimento da pesca possibilita investimentos em atividades complementares, simultaneamente intensificando e diversificando a pequena produção. Com posse segura dos lagos e organizações coletivas que garantam acesso igual e punição de infratores, a pesca poderia ser gerenciada de forma sustentável para manter ou mesmo aumentar a produção pesqueira (Ostrom, 1990; MacKenzie, 1992). Além disso, como a pesca é mais produtiva do que a pecuária, haveria um incentivo para manipular o ambiente em função do manejo pesqueiro em vez da pecuária extensiva, mantendo a cobertura florestal e limitando o número de reses pastando nos campos. Em geral, o desenvolvimento pesqueiro seguindo essa trajetória geraria um processo de desenvolvimento rural que poderia resultar no desenvolvimento de uma população de pequenos produtores estáveis e relativamente prósperos, baseado no manejo sustentável dos ecossistemas de várzea que asseguram a economia e sociedade da várzea.

\section{Barreiras para a implementação do modelo de manejo comunitário}

Até agora concentramos na descrição do Modelo de Manejo Comunitário e na avaliação de seu potencial para servir como base de um programa para o desenvolvimento da pesca regional. Nessa parte avaliamos a viabilidade de implementar esse modelo numa escala regional. Neste contexto, duas importantes questões devem ser abordadas: a capacidade organizacional comunitária e o sistema fundiário e estrutura agrária da várzea, que constituem importantes barreiras, até agora não resolvidas, que dificultam a implementação do Modelo Comunitário.

\subsection{Manejo coletivo}

Reservas de lago parecem ser uma contradição da tese de Hardin (1968) da "tragédia dos comuns". A dinâmica de interesse individual, que é responsável pela "tragédia", é um fator com o qual organizações comunitárias têm que lidar para o manejo coletivo funcionar (Ostrom 1990). Nesse aspecto, o maior desafio para o desenvolvimento de sistemas funcionais de reservas comunitárias de lago, não é técnico mas organizacional; como por exenplo, criar organizações coletivas eficazes e resilientes, capazes de manejarem a pesca local de forma sustentável. O problema da limitada capacidade organizacional é crítico. Se organizações comunitárias não podem ser desenvolvidas, o modelo comunitário simplesmente não é uma alternativa. Como estratégia de manejo seria pouco diferente na prática de uma pescaria de livre acesso, mas com a complicação adicional de que a população varzeira controlaria o acesso 
ao recurso, obstruindo tentativas de aumentar a eficiência e sustentabilidade do manejo pesqueiro.

Em toda a Amazônia brasileira, as atuais comunidades rurais são resultados dos esforços de programas da Igreja Católica iniciados na década de 60. A organização de pequenos produtores e pescadores intensificou-se com o desenvolvimento do movimento de trabalhadores rurais na década de 80 (Leroy, 1991; Schönenberg, 1994). E o sucesso desses programas na criação de comunidades fisicamente coerentes e na capacitação de líderes comunitários nas técnicas básicas de organização é sem dúvida impressionante. As organizações comunitárias que resultaram foram criadas para atender às necessidades organizacionais da Igreja e depois aos objetivos políticos do movimento de trabalhadores rurais e não do manejo coletivo de recursos naturais. Com o declínio desses movimentos na década de 90, as estruturas organizacionais têm sido mantidas pela Igreja em apoio as suas atividades religiosas. Embora essas estruturas comunitárias ${ }^{4}$ tenham fornecido a base para as tentativas mais bemsucedidas de desenvolvimento de reservas de lago comunitárias (Lima, 1994; CPT, 1992b), elas são em geral muito frágeis. Sucessos locais tendem a refletir os esforços de indivíduos excepcionalmente capazes e não de organizações comunitárias mais duradouras. Mesmo onde existem organizações bem-sucedidas, seus esforços são freqüentemente prejudicados pelo fato de que instituições e líderes comunitários carecem da autoridade legal para impor decisões e punir infratores.

Com respeito ao manejo comunitário da pesca de lago, o problema é mais grave pelo fato de que não há base legal para reservas de lago. A prática de excluir pessoas que não são membros da comunidade é ilegal, contradizendo diretamente a legislação federal permitindo livre acesso às vias aquáticas interiores (Isaac et al., 1994). Além disso, as medidas mais freqüentemente utilizadas por comunidades, restrições no uso de malhadeiras e medidas indiretas para limitar a captura, não têm base legal. Um resultado é que a maioria dos sistemas comunitários de manejo são bastante simplísticos, refletindo a limitada capacidade de organizações comunitárias de controlar a atividade pesqueira.

Para reservas de lago tornarem-se um componente significativo de uma política pesqueira regional, esses impedimentos ao desenvolvimento de sistemas funcionais de manejo comunitário têm que ser superados. Existem algumas tentativas de resolver essas deficiências. Em vários locais na várzea amazônica, comunidades, Colônias de Pescadores e organizações de apoio, estão desenvolvendo experimentos promissores no manejo coletivo da pesca (veja Ruffino nesse volume, Lima, 1994, e CPT, 1992b, e McGrath et al., 1993a). Embora o IBAMA tenha mostrado cada vez mais interesse em apoiar a participação dos usuários no manejo pesqueiro, esse apoio ainda não resultou nas mudanças da política pesqueira necessárias para esses experimentos serem bem-sucedidos em médio e longo prazos. Entretanto, mudanças na política pesqueira não serão suficientes. É essencial uma abordagem mais sistemática para capacitar líderes comunitários com as ferramentas necessárias para administrar organizações coletivas para o gerenciamento pesqueiro local.

\footnotetext{
4 A Colônia de Pescadores Z-20 de Santarém, como muitas outras organizações de base na Amazônia, deve muito de sua capacidade organizacional atual aos esforços de programas e organizações ligadas à Igreja Católica. A maioria das lideranças da Colônia receberam seu treinamento da Igreja Católica, e foram beneficadas pelo apoio de grupos ligados à Igreja como a FASE (Federação de Órgãos para Assistência Social e Educacional) e à Comissão Pastoral da Terra.
} 


\subsection{Sistema fundiário e estrutura agrária}

O outro principal desafio à implementação de reservas de lago é a ambigüidade dos sistemas fundiários de várzea e a estrutura agrária prevalecente (Santos Vieira 1992). A situação é complicada pelo fato de que os sistemas fundiários estão sofrendo mudanças profundas e contraditórias: de um lado, uma tendência à privatização, do outro, a tendência para a formalização de relações de propriedade comum. Além disso, o conceito de reserva de lago e a luta para o controle dos recursos dos lagos freqüentemente apóia-se nos princípios contraditórios de livre acesso e propriedade individual.

Em princípio, a várzea é propriedade do Estado. Propriedade privada não existe na várzea, embora o Estado possa conceder o direito de uso de longo prazo para indivíduos. $\mathrm{Na}$ prática, entretanto, a maior parte da várzea tem sido propriedade privada desde a época colonial. Hoje, embora poucos proprietários tenham se preocupado em conseguir a documentação formal do governo federal para legitimar seu direito de uso, a maioria tem documentos de compra e venda, e propriedades de várzea são compradas e vendidas normalmente.

A ambigüidade do sistema fundiário é intensificada pela atual estrutura agrária. Enquanto os campos naturais de várzea têm sido tradicionalmente tratados como uma área comum, com a expansão da pecuária na várzea, essas áreas estão sendo incorporadas em propriedades privadas. Como resultado desse processo, partes significativas dos sistemas de lagos dos quais muitas comunidades de várzea dependem, estão localizadas "dentro" ou estão rodeados por fazendas individuais. Isto pode ser um problema porque fazendeiros e pequenos produtores usam os mesmos critérios para justificar o controle sobre os lagos. Assim, em muitas áreas, comunidades de várzea estão explorando recursos que pela sua própria definição são da propriedade de fazendeiros vizinhos. Na ilha de Ituqui, município de Santarém, por exemplo, $76 \%$ da ilha é controlada por um pequeno grupo de grandes proprietários, enquanto seis comunidades da ilha controlam somente os $24 \%$ restantes (Figura 6). Além disso, vários dos maiores e mais importantes lagos estão dentro dos limites de uma única propriedade. Se esse fazendeiro proibisse acesso a estes lagos, os pescadores perderiam o acesso a uma parte importante dos recursos pesqueiros da ilha.

Em geral, o fato das comunidades dependerem de lagos que são reconhecidos como dentro de fazendas vizinhas não tem sido tão problemático como no Marajó oriental (Brabo 1981). Embora conflitos e disputas pelo acesso aos lagos sejam freqüentes na região como um todo, as comunidades e fazendeiros locais geralmente conseguem coexistir pacificamente e pescadores comunitários têm acesso mais ou menos livres aos lagos "dentro" de fazendas. No Ituqui, por exemplo, esforços comunitários para manejar os lagos têm o apoio implícito dos fazendeiros locais.

Entretanto, a formalização de reservas de lago ou de controle comunitário dos lagos poderia ameaçar essas relações tradicionais de acesso e uso. Fazendeiros provavelmente veriam reservas de lago como uma ameaça à legitimidade de suas reivindicações de posse. Mesmo se for argumentado que as reservas de lago são para manejar peixes e não propriedade de várzea em si, o fato de que durante parte do ano o lago cobre toda a várzea, complica bastante a distinção entre o lago e a propriedade de várzea como um todo. Grandes proprietários responderiam a essa ameaça tomando posse dos lagos dentro de suas propriedades, expulsando pescadores locais e cortando o acesso das comunidades aos recursos pesqueiros 
dos lagos dos quais tradicionalmente têm dependido. Essa tendência está bem avançada na parte oriental da Ilha de Marajó (Brabo 1981).

O conflito entre comunidades e fazendeiros vizinhos levanta uma outra questão complicada: quais critérios devem ser usados para avaliar as reivindicações de diferentes tipos de proprietários ("fazendeiros" e "comunidades") e outros grupos organizados para acesso e controle dos recursos pesqueiros locais? Enquanto proprietários de várzea, baseiam suas reivindicações nos mesmos conceitos de relações de propriedade, esses conceitos estão em conflito com o conceito de livre acesso que é a base da política pesqueira nacional. O Estado não reconhece o controle privado dos recursos pesqueiros dos lagos e, conseqüentemente, apóia o direito à pesca em qualquer corpo d'água que os pescadores possam alcançar por barco. Isso deixa as comunidades numa posição contraditória de aparentemente apoiar o princípio de livre acesso quando pescando em lagos dentro de grandes propriedades e reivindicando o princípio de acesso restrito e controle local quando pescadores de fora tentam entrar nos lagos dentro do território da comunidade. Esse problema é mais intenso quando leva em conta a falta de definição sobre o que constitui uma "comunidade" e não simplesmente um grupo de proprietários. Quando é, por exemplo, que uma reivindicação de posse é uma reivindicação comunitária válida, e quando é que é simplesmente uma tentativa de um grupo de proprietários de se apropriar dos recursos locais.

Formalização de reservas de lago como categoria de uso do solo ou propriedade terá conseqüências profundas no sistema fundiário e na estrutura agrária atual da várzea. Se a história da reforma agrária no Brasil fornece algum indicativo, resistência a essas mudanças será feroz. Entretanto, se essas questões não forem resolvidas, é duvidoso que reservas de lago possam chegar a ser uma estratégia de manejo efetiva numa escala regional.

\section{Conclusão}

A pesca amazônica está numa fase crítica de seu desenvolvimento. As duas opções que estão surgindo são baseadas em diferentes interpretações da situação atual, têm diferentes premissas e prioridades, levam a diferentes políticas pesqueiras e a diferentes resultados para a pesca regional. Sobre ambos os modelos pairam questionamentos sérios a respeito de sua eficácia sob condições amazônicas. Enquanto essas duas alternativas são conceituais e teoricamente coerentes, em ambos os casos existem barreiras a sua implementação efetiva. Em nenhum dos casos existem as condições institucionais mínimas necessárias para implementar o modelo com segurança que possibilite alcançar os objetivos a médio e longo prazo.

As duas não são opções iguais, no entanto, têm o mesmo objetivo: é o desenvolvimento sustentável da várzea amazônica. Mesmo se as condições institucionais básicas do Modelo Tecnocrata fossem encontradas, o desempenho desse modelo em outras partes do mundo não seria animador, mesmo para sistemas pesqueiros bem mais simples (McGoodwin, 1990; McEvoy, 1990; Swardson 1994; Weber, 1993-1994). A eficácia dessa abordagem a médio e longo prazos é ainda mais duvidosa no contexto do desenvolvimento pesqueiro amazônico. Além disso, mesmo se o Modelo Tecnocrata fosse funcionar no sentido estrito de manter uma captura maior, as conseqüências sociais e ecológicas seriam problemáticas (McGoodwin, 1990; Neal, 1982; McCully, 1992). O desenvolvimento pesqueiro, especialmente da pesca de várzea, não pode ser tratado como se fosse independente do contexto econômico, social e ecológico da várzea (Junk, 1989; Goulding, 1996; McGrath et al. 1993a). 
Embora barreiras à implementação efetiva do Modelo Comunitário sejam consideráveis, ele parece ser a maneira mais efetiva de garantir o desenvolvimento sustentável não apenas da pesca, mas também da várzea amazônica como um todo. Três aspectos do Modelo Comunitário são especialmente relevantes. Primeiro, o Modelo Comunitário fortalece organizações locais de pescadores, o grupo de usuários mais interessados no manejo sustentável da pesca. Segundo, ele assegura o acesso do pequeno produtor à pesca local, o elemento central da economia do pequeno produtor. Terceiro, ele fornece uma estrutura para desenvolver a pesca nos lagos como o setor principal dentro de uma estratégia global ao desenvolvimento sustentável dos recursos da várzea.

Mas isso não implica em simplesmente passar responsabilidade do gerenciamento da pesca para as comunidades de várzea e organizações de pescadores, porque a implementação bem-sucedida do Modelo Comunitário dependerá do tipo e qualidade do apoio governamental nos níveis regional, estadual e municipal. Nesse contexto, é necessário um amplo programa governamental que tenha como objetivo fortalecer a capacidade institucional local de gerenciar não somente a pesca mas também o desenvolvimento sustentável dos recursos de várzea como um todo. Tal programa deveria enfocar três áreas: a legislação pesqueira, pesquisa sobre a ecologia pesqueira da várzea, e a capacitação de lideranças.

Primeiro, é necessária uma revisão completa na legislação pesqueira brasileira a fim de permitir a descentralização do gerenciamento do nível nacional para os níveis da bacia, Estado, município e comunidade, para que grupos locais de usuários tenham a autoridade necessária para manejar a pesca local de forma efetiva ${ }^{5}$. Essa descentralização deve fazer parte de um plano de gerenciamento pesqueiro amazônico, que distribua a autoridade de manejo para o nível regional apropriado e forneça um programa de política pesqueira que oriente a tomada de decisões de manejo nos níveis regional, municipal e local. Dentro desse programa, o Estado teria o papel central, não somente como a fonte de poder jurídico para fiscalizar decisões locais, mas também para avaliar reivindicações sobre a posse dos lagos, monitorar o desempenho de reservas de lago comunitárias e fornecer assistência técnica para organizações locais de manejo pesqueiro.

Segundo, a ciência também tem um papel crucial. A proposta não é de promover o manejo tradicional per se, mas de modernizar a pesca de várzea aproveitando o conhecimento tradicional e a utilização dos recursos pesqueiros de várzea. Para isso, o sucesso do Modelo Comunitário dependerá da capacidade da comunidade científica em sistematizar e ampliar o conhecimento local através de pesquisas sobre a ecologia pesqueira da várzea, a biologia de espécies de valor comercial, e melhoramentos na tecnologia de captura, processamento e armazenamento do pescado.

\footnotetext{
5 O setor de gerenciamento pesqueiro do IBAMA está reformulando a política pesqueira para a Amazônia. Entretanto, não parace que as revisões afetarão algumas das premissas fundamentais da política pesqueira como livre acesso, nem fornecerão mecanismos para decentralizar a tomada de decisões de manejo até o nível de grupos locais de usuários.
} 
Finalmente, o fator mais importante para a implantação bem-sucedida do Modelo é a presença de gerentes comunitários capazes de adaptar o Modelo Comunitário às condições sociais, econômicas e ambientais locais. Para isto, o Estado precisa investir na capacitação de uma nova geração de lideranças rurais, preparadas para administrar organizações coletivas e manejar recursos de propriedade comum. Se essas três questões puderem ser atendidas, talvez seja possível superar as barreiras que enfrenta o Modelo Comunitário, e assim realizar a oportunidade que o desenvolvimento pesqueiro representa, em termos de aumento da qualidade de vida do pequeno produtor e ao mesmo tempo manter a biodiversidade e integridade funcional dos ecossistemas de várzea.

\section{Referências bibliográficas}

ANDERSON, L. The economics of fisheries management. Johns Hopkins University Press. Baltimore, MD, 1986.

BARTHEM, R., Ribeiro, M., and Petrere, M. Life strategies of some long-distance migratory catfishes in relation to hydroelectric dams in the Amazon basin. Biological conservation 55: 339-345, 1991.

BARTHEM, R. B., Guerra, H., and Valderrama, M. Diagnóstico de los recursos bidrobiologicos de la Amazonia. Tratado de Cooperación Amazónica, Lima, 1995.

BAYLEY, P. and PETRERE, M. Amazon fisheries: assessment methods, current status and management options. Canadian special publications fisheries and aquatic science 106: 385-98, 1989.

BAYLEY, P. Understanding large river-floodplain ecosystems. Bioscience 45(3): 153-157, 1995a.

Sustainability in Tropical inland fisheries: the manager's dilemma and a proposed solution, p. 321-328. In: M. Munasinghe and W. Shearer (Eds), Defining and Measuring Sustainability: the biogeophysical foundations. The World Bank, Washington, D.C., 1995b.

BERKES, F. (Ed). Common property resources: ecology and community-based sustainable development. Belhaven Press, London, 1989.

BRABO, M. J. C. Pescadores, geleiros, fazendeiros: os conflitos da pesca em Cachoeira do Arari. Boletim do Museu Paraense Emilio Goeldi. Antropologia No. 77. Belém, Pará, 1981.

BROMLEY, D. and Cernea, M. The management of common property resources. World Bank discussion paper No. 57, The World Bank, Washington, D.C., 1989.

C. P. T. Ribeirinhos: Uma estação de luta. Dossiê 1992. Comissão Pastoral da Terra, Regional Amazonas e Roraima, Manaus, 1992a.

C. P. T. Os Ribeirinhos: Preservação dos Lagos, defesa do meio ambiente e a pesca comercial. Comissão Pastoral da Terra, Regional Amazonas e Roraima, Manaus, 1992b.

CHAPMAN, M. The political ecology of fisheries depletion. In: Amazonia. Environmental conservation 16(4), p. 331-337, 1989.

CHERNELA, J. Indigenous fishing in the Neotropics: the Tukanoan Unanano of the Blackwater Uaupés river basin in Brazil and Colombia. Interciência 12, p. 78-86, 1985. 
CORDELL, J. C. and McKean, M. A. Sea tenure in Bahia, Brazil. p. 85-112. In: Proceedings of the conference on common property resource management, National Academy Press: Washington, D.C., 1986.

DENEVAN, W. M. Ecological heterogeneity and horizontal zonation of agriculture in the Amazon floodplain, p. 311-336. In: M. Schmink and C. H. Wood (Eds.), Frontier Expansion in Amazonia. University of Florida Press: Gainesville, 1984.

FAIRLIE, S., Hagler, M. and O'Riordan, B. The Politics of Overfishing. The Ecologist 25(2/3), p. 46-73, 1994.

FEENY, D., Berkes, F., McCay, B. and Acheson, J. The tragedy of the commons: twenty-two years later. Human Ecology 18(1), p. 1-19, 1990.

FURTADO, L. G. Características gerais e problemas da pesca Amazônica no Pará. Boletim do Museu Paraense Emilio Goeldi. Antropologia. 6(1), p. 41-93, 1990.

GENTIL, J. A juta na agricultura na várzea na área de Santarém Médio Amazonas. Boletim do Museu Paraense Emilio Goeldi, Antropologia, 79, p. 1-50, 1988.

GOULDING, M. The fishes and the forest. Berkeley: University of California Press, 1980.

Amazonian fisheries, p. 189-210. In: Moran, E. (Ed.), The Dilemma of Amazonian development. Colorado: Westview Press, 1983. - Amazon: The flooded forest. The BBC, London, 1989. . Flooded forests of the Amazon. Scientific American 266(3), p. 114-120, 1993.

Pescarias amazônicas, proteção de hábitats e fazendas nas várzeas: uma visão ecológica e econômica. Consultant's report to the Pilot Program for the Conservation of the Amazon Rainforest, World Bank, Brasília, D.F., 1996.

HAGLER, M. Deforestation of the deep: fishing and the state of the oceans. The Ecologist 25(2/3), p. 74-79, 1994.

HARDIN, G. The tragedy of the commons. Science 162, p. 1243-8, 1968.

HARTMANN, W. Conflitos de pesca em águas interiores da Amazônia e tentativas para sua solução, p. 103-118. In: Pesca Artesanal: Tradição e Modernidade. III. Encontro de Ciências Sociais e o Mar. Programa de Pesquisa e Conservação de Áreas Úmidas no Brasil. São Paulo, 1989.

HECHT, S. The logic of livestock and deforestation in Amazonia. Bioscience 43(10), p. 687695), 1993.

HECHT, S. B., Anderson, A.B. and May P. The subsidy from nature: shifting cultivation, successional palm forests, and rural development. Human organization 47(1), p. 25-35, 1988.

ISAAC, V., Rocha, V. and Mota, S. Algumas considerações sobre a legislação da "piracema" e outras restrições da pesca do Médio Amazonas p. 187-211. In: Furtado, L., Mello, A. and Leitão, W. (Eds) Povos das Águas: Realidade e Perspectiva na Amazônia. Museu Paraense Emilio Goeldi, Belém, 1993. 
JUNK, W. Ecology of the varzea of Amazonian whitewater rivers, p. 215-244. In: H. Sioli (Ed.) The Amazon: Limnology and Landscape Ecology of a Mighty Tropical River and its Basin. Dordrecht: W. Junk, 1984a.

Ecology, fisheries and fish culture in Amazonia, p. 443-475. In: H. Sioli (Ed.) The Amazon: Limnology and Landscape Ecology of a Mighty Tropical River and Its Basin. Dordrecht: Dr. W. Junk Publishers, 1984b

The use of Amazonian floodplains under an ecological perspective. Interciência 14(6), p. 317-321, 1989.

JUNK, W., P. BAYLEY, and R. SPARKS. The flood pulse concept in river-floodplain systems. Canadian special Publications in fisheries aquatic science 106, p. 110-127, 1989.

Kurien, J. Resistance to multinationals in Indian waters. The Ecologist 25(2/3), p. 115-119, 1994.

Larkin, P.A. An epitaph for the concept of maximum sustained yield. Transactions of the American fisheries society 106(1), p. 1-11, 1977.

Larkin, P.A. Fisheries management: an essay for ecologists. Annual review of ecology and systematics 9, p. 57-73, 1978.

LEROY, J. Uma chama na Amazônia. FASE, Rio de Janeiro, 1992.

LIMA, D. A implantação de uma unidade de conservação em área de várzea: a experiência de Mamirauá, p. 403-412. In: M. A. D’Incao and I Maciel da Oliveira (orgs.) Amazônia e a crise da modernização. Museu Paraense Emilio Goeldi, Belém, 1994.

McCAY, B. and ACHESON, J. The question of the commons: the culture and ecology of communal resources. Tucson: University of Arizona Press, 1987.

McCULLY, P. FAO and Fisheries Development. Ecologist21(2), p. 77-80, 1991.

McEVOY, A. The fishermen's problem. Stanford University Press, Palo Alto, California, 1990.

McGOODWIN, R. Crisis in the world's fisheries. Satnford University Press, Stanford, 1990.

McGRATH, D., CASTRO, F. de, FUTEMMA, C., AMARAL, B., and CALABRIA, J. Fisheries and resource management on the Lower Amazon floodplain. Human ecology 21(2), p. 167-195, 1993a.

McGrath, D., CASTRO, F., FUTEMMA, C. AMARAL, B. and CALABRIA, J. Manejo comunitário da pesca nos lagos de várzea do Baixo Amazonas, p. 213-229. In: Furtado, L, Mello, A., and Leitão, W. Povos das Águas: Realidade e Perspectiva na Amazônia. Museu Paraense Emilio Goeldi, Belém, Pará, 1993b.

McGRATH, D., CASTRO, F. de, and FUTEMMA, C. Reservas de lago e o manejo comunitário da pesca no Baixo Amazonas: uma avaliação preliminar. In: D'Incao, M.A. and Silveira, I.M. (Eds) Amaz̧ônia e a crise da modernização. Museu Paraense Emílio Goeldi, Belém, Pará, 1994.

MAcKENZIE, W. An introduction to the economics of fisheries management. FAO Fisheries Technical Paper 226, FAO, Rome, 1992. 
MATHEWS, D. Commons versus open access: the Canadian experience. The Ecologist 25(2/3), p. 86-96, 1994.

MATTOS, M. and Uhl, C. Economic and ecological perspectives on ranching in the Eastern Amazon. World development 22(2), p. 145-158, 1994.

MESCHKAT, A. Report to the Government of Brazil on the Fisheries of the Amazon Region. Technical report 1305. Food and Agriculture Organization, United Nations: Rome, 1960.

NEAL, R. Dilemma of the small-scale fishermen. ICLARM Newsletter (July, 1982), p. 7-9, 1982.

NIELSEN, L. The evolution of fisheries management philosophy. Marine Fisheries Review (December, 1976), p. 15-22, 1976.

OSTRUM, E. Governing the commons. Cambridge University Press, Cambridge, 1990.

PIÑEDO-VASQUEZ, M., Zarin, D. and Jipp, P. Community forest and lake reserves in the Peruvian Amazon: a local alternative for sustainable use of tropical forests, p. 79-86. In: D. Nepstad and S. Schwartzman (Eds) Non-timber Products from Tropical Forests. Advances in Economic Botany, Volume 9, 1992.

SANTOS VIERA, R. Várzeas Amąônicas e a Legislação Ambiental Brasileira. INPA, Manaus, AM, 1992.

SCHÖNENBERG, R. As formas institucionais e organizacionais, de articular interesses na área da pesca no Baixo Amazonas em Particular, e na Amazônia em geral. Relatório Preliminar para Projeto IARA, IBAMA, Santarém, Pará, 1994.

SCOTT, A. Development of economic theory on fisheries regulation. J. of Fisheries Research Board of Canada 36, p. 725-741, 1979.

SMITH, N. A pesca no rio Amazonas. Manaus: INPA, 1979.

The impact of cultural and ecological change on Amazonian fisheries. Biological conservation 32, p. 355-373, 1985.

SPARKS, R. Need for ecosystem management of large rivers and their floodplains. Bioscience 45(3), p. 168-182, 1995.

STOCKS, A. Resource management in an Amazon varzea lake ecosystem: the Cocamilla case, p. 108-120. In: McCay, B. and Acheson, J. (Eds), The Question of the Commons: the culture and ecology of communal resources. Tucson: University of Arizona Press, 1987.

SWARDSON, A. Net losses: fishing decimates oceans "unlimited" Bounty. Washington Post (August 14th), Washington, D.C., 1994.

WEBER, P. Abandoned Seas: Reversing the decline of the Oceans. Worldwatch Paper 116. Washington, D.C., 1993.

WEBER, Net Loss: Fish, Jobs, and the Marine Environment. Worldwatch Paper 120. Washington, D.C., 1994.

WELCOMME, R. L. River Fisheries. FAO Technical Paper 262, Food and Agricultural Organization, Rome, Italy, 1985. 
